Roberta Mendes Da Costa Martins

\title{
A proposta pedagógica impressa e a proposta praticada
}

Monografia apresentada à Pontifícia Universidade Católica do Rio de Janeiro como requisito parcial à obtenção do título de especialista em Educação Infantil.

Orientadora: Rejane Brandão Siqueira 
Roberta Mendes Da Costa Martins

A proposta pedagógica impressa e

a proposta praticada

Monografia apresentada à Pontifícia Universidade Católica do Rio de Janeiro como requisito parcial à obtenção do título especialista em Educação Infantil.

Orientadora: Rejane Brandão Siqueira

Coordenação Central de Extensão Curso de Especialização em Educação Infantil Perspectiva de Trabalho em Creches e Pré-Escolas

Rio de Janeiro

Outubro 2016 


\section{Agradecimentos}

Ao Senhor, primeiramente, por mais uma vez me sustentar e abrir meu entendimento para os estudos.

A minha filha que mais uma vez cooperou e entendendo meus momentos de ausência para me dedicar aos estudos.

Aos meus pais por contribuírem financeiramente e em oração para eu continuar e não desistir no meio do caminho.

Aos meus irmãos por torcerem por mim a cada etapa alcançada. Ao meu noivo por me apoiar e incentivar.

A minha orientadora por ser tão presente e dedicada, sem ela esse trabalho não teria sido tão bom.

Ao meu trabalho e as crianças, sem eles não seria possível fazer essa pesquisa. 


\section{Resumo}

A Educação Infantil foi legitimada enquanto dever do estado e direito das crianças com a Constituição de 1988 representando uma valiosa contribuição na garantia dos direitos das crianças. Partindo deste princípio buscamos fundamentar essa reflexão traçando o contexto histórico da educação infantil com recortes na época escravista e o surgimento da Roda dos Expostos para compor a construção do olhar para as crianças pequenas e assim apresentar como se concebeu a creche no Brasil. No decorrer da pesquisa apresentamos alguns artigos das Diretrizes Curriculares Nacionais para a Educação Infantil/ 2009 que compõe a natureza da proposta pedagógica para as instituições de educação infantil, além das contribuições de Kramer, Corsino, Kishimoto e Veiga sobre currículo, proposta e planejamento. Refletir sobre o papel da proposta pedagógica e sua articulação na prática cotidiana da Educação Infantil é o objetivo a que se propõe o presente trabalho. A proposta pedagógica de uma instituição é o documento que apresenta a identidade da instituição, reunindo suas bases teóricas e fundamentação para as práticas então realizadas. A reflexão se concretiza com a análise da proposta pedagógica de uma instituição privada e a observação das rotinas diárias a fim de identificar como ocorria a sua concretização na prática.

\section{Palavras-chave}

Proposta pedagógica; planejamento; cotidiano 


\section{Sumário}

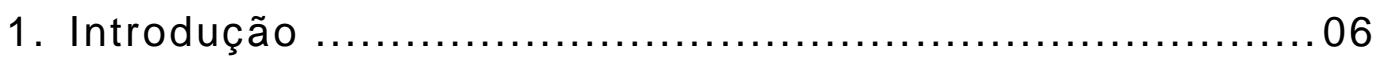

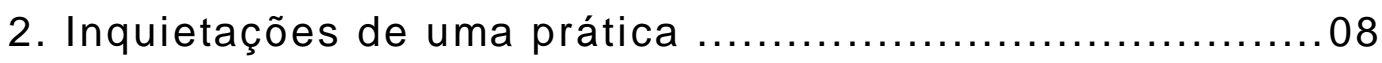

2.1. História e política ......................................... 08

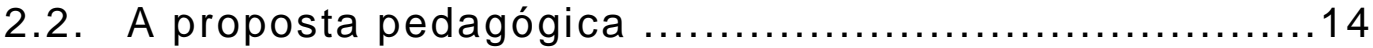

2.3. E quem faz a proposta? ............................... 15

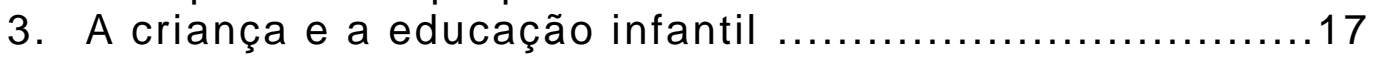

3.1. Educação infantil: espaço de construção de

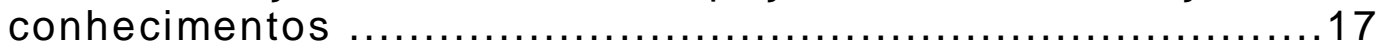

3.2. Educação infantil: espaço de formação de princípios 19

3.3. Educação infantil: espaço de função sociopolítica e pedagógica 23

4. A proposta no cotidiano - espaço, rotina, brincadeiras e interações ....26

4.1. Qual escola é essa? .....................................27

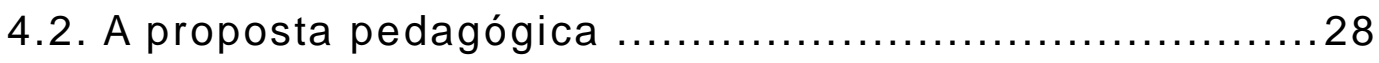

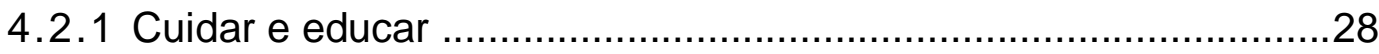

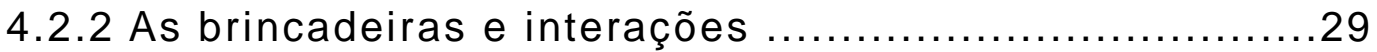

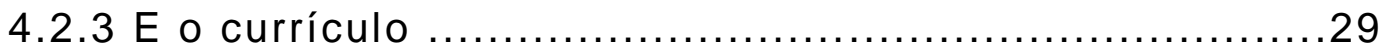

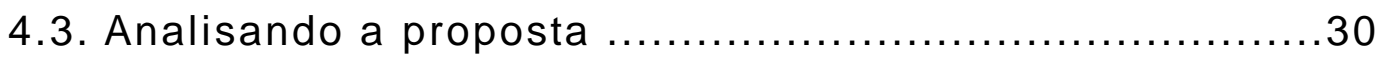

4.4. E na prática, como é que acontece? .......................31

5. Considerações Finais ......................................... 35

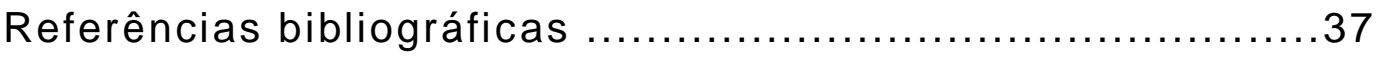




\section{1 \\ Introdução}

A passagem da educação infantil do sistema assistencial para o sistema educacional é uma conquista ímpar para o desenvolvimento das crianças de 0 a 5 anos. A Educação como direito de todas as crianças é um marco na história desse país injusto e desigual que, não sem reticências, carece de uma normativa para reconhecer a criança como cidadã, sujeito de direitos.

$\mathrm{Na}$ verdade, o direito estabelecido é apenas o pontapé inicial para um processo que, mesmo passado vinte oito anos da constituinte, ainda está em execução. O direito da criança pequena a educação é ainda alvo de múltiplos combates na arena política.

Mas, o fato de estar relacionado entre as etapas da educação básica da Lei de Diretrizes e Bases da Educação Nacional impulsiona a ação governamental no sentido de garantir esse direito a todas as crianças.

Ao estar relacionada entre as etapas educativas, a educação infantil oferecida em creches e pré-escolas deve ter uma proposta pedagógica sistematizada e concretizada em suas práticas cotidianas. E, como regulador das ações locais, o MEC define as Diretrizes Curriculares Nacionais para a Educação Infantil (Brasil. 2009) onde se institui as Diretrizes Curriculares Nacionais para a Educação Infantil a serem observadas na organização de propostas pedagógicas na Educação Infantil.

As Diretrizes Curriculares Nacionais para a Educação Infantil articulamse com as Diretrizes Curriculares Nacionais da Educação Básica e reúnem princípios, fundamentos e procedimentos definidos pela Câmara de Educação Básica do Conselho Nacional de Educação, para orientar as políticas públicas na área e a elaboração, planejamento, execução e avaliação de propostas pedagógicas e curriculares. (BRASIL, 2009)

Este trabalho surge de uma inquietação provocada no transcorrer das aulas de Alternativas Pedagógicas e Pesquisa em Educação, disciplinas ministradas por professoras distintas, mas na Educação sempre ocorre à interdisciplinaridade. Algumas angústias perpetuam sobre esse estudo, entre elas a busca de compreender como acontece o diálogo entre a teoria e a prática cotidiana nas salas da Educação Infantil. 
Com o objetivo de analisar a proposta pedagógica de uma escola privada dialogando com os planejamentos semanais e observação das práticas diárias, pois a proposta pedagógica se concebe nas práticas, esse estudo vai exigir um resgate ao contexto histórico da educação infantil e a evolução política deste campo.

Para além da história e política da Educação Infantil, buscaremos trazer alguns apontamentos das Diretrizes Curriculares para a Educação Infantil e nos apoiamos nas contribuições de Kramer, Kishimoto e Corsino a cerca das discussões em torno do currículo e planejamento na educação infantil.

Este trabalho propõe uma discussão sobre a concepção de infância e o olhar com respeito sobre essas na elaboração da proposta pedagógica, tendo como o resultado o planejamento semanal e sua consolidação através das práticas pedagógicas.

Nessa perspectiva, consideramos iniciar essa análise com um breve histórico sobre o surgimento da creche no Brasil para embasar os progressos políticos que ocorreram, além de retomar questões sobre a concepção de infância.

No segundo capítulo serão apresentados os documentos elaborados pelo MEC que fundamentam as propostas curriculares para as instâncias públicas e privadas (Diretrizes Curriculares para a Educação Infantil) e a partir do que se propõe serão tecidas algumas considerações sobre o planejamento na educação infantil.

Para fins deste trabalho, será apresentado o resultado da análise da proposta pedagógica de uma escola e observações da prática cotidiana a partir de alguns questionamentos em torno do processo de construção da proposta pedagógica e os planejamentos semanais articulados às práticas cotidianas - Como é construída a proposta curricular? Existe um projeto que articula com a proposta? Esses e outros questionamentos são trazidos nessa escrita. 


\section{2 Inquietações de uma prática}

Para início de conversa, pretendemos trazer alguns apontamentos sobre a influência europeia na construção do olhar para a educação/atendimento às crianças pequenas no Brasil do final do século XVIII e XIX. Buscamos fundamentar esta reflexão, contextualizando a época escravista e o surgimento da Roda dos Expostos com a intenção de pensar como se deu a construção do olhar para as crianças pequenas e a partir disso apresentar como foi instaurada a creche no Brasil.

Vale à pena destacar que essas influências no olhar para a educação das crianças pequenas no Brasil se dá inicialmente com características voltadas para o assistencialismo e irão se modificando impulsionadas pelos estudos e propostas dos precursores da educação infantil como -Friedrich Frobel, Jean Piaget, Johann Heinrich Pestalozzi entre outros que vão contribuir para a construção do olhar pedagógico desse atendimento.

\section{1}

\section{História e política}

Segundo Faria (1997), entre os séculos XVIII e XIX não havia um sentimento de criança/infância, estes, se filhos de escravos eram amarrados aos corpos das mães e incorporados gradativamente ao trabalho. Por outro lado, as escravas que eram escolhidas para serem amas-de-leite destinavam seus filhos à Roda dos Expostos.

Nesse período, a mortalidade infantil não despertava sofrimentos devido a um sentimento da criança enquanto "anjinho", puro e ainda intocado pelo pecado. Essa conotação angelical era atribuída à criança branca ou negra.

O nome Roda, pelo qual tornou-se mais conhecida, deve-se à assimilação da instituição ao dispositivo onde eram depositadas as crianças. Trata-se de um cilindro cuja superfície lateral é aberta em um dos lados e que gira em torno de um eixo vertical. O lado fechado ficava voltado para a rua. Uma campainha exterior é colocada nas proximidades. Se a mulher deseja entregar um recém nascido, ela avisa à pessoa de plantão tocando a campainha. (CIVILETTI, 1991, p.33-34)

Em outras palavras, as crianças originadas da Roda eram, em grande parte, filhos de escravas cujos proprietários não queriam se responsabilizar pela criação, ou, em outros casos, essas mães escravas optavam por abandonar seus filhos na 
tentativa de livrá-los da escravidão e de serem posteriormente adotados por famílias abastadas, que por eles pagavam um dote.

Em 1738, Romão Mattos Duarte funda a Casa dos Expostos do Rio de Janeiro. Em 1882, ao apresentar o atendimento realizado no Brasil à infância abandonada no Congrès Internacional de la IEnfance, Araújo(1883) acusa a existência de Rodas em quase todas as províncias brasileiras. (CIVILETTI, 1991, p.34)

As crianças entregues à Roda eram geralmente adotadas, mas os índices de mortalidade eram enormes e pouco se sabia do destino das sobreviventes. Diante desse panorama, há um questionamento quanto à complexidade dessa informação: Será que havia oportunidades para as outras crianças oriundas da roda quando não fossem adotadas ou estas ficavam a margem da sociedade? Sem dúvida, há estudos que já se debruçaram sobre essa temática contudo não é objetivo do presente trabalho apresentar as respostas possíveis mas levantar a questão.

A partir da segunda metade do século XIX, a prática de uso de amas-de-leite foi alvo de críticas por parte de abolicionistas e médicos higienistas. Os médicos iniciam uma luta em prol da reeducação física, moral e intelectual da mãe burguesa criticando a Roda dos Expostos e o uso das amas-de-leite. Com efeito, vieram as críticas quanto ao uso das mamadeiras e, portanto as mães teriam que amamentar seus filhos, mas ainda assim estas mulheres precisavam dos serviços das escravas e ex-escravas. A partir de 1871, a Roda começa a ser menos utilizada e um novo problema surge: o que fazer com os filhos ex- escravas designadas para realizar os serviços domésticos. É neste contexto que começa a esboçar-se o surgimento da creche no Brasil. (CIVILETTI,1991)

As profundas transformações sociais e políticas abrem no Brasil, o caminho para a construção de uma nova sociedade de tipo capitalista e urbano-industrial e a creche se instaura, no final do século XIX como local onde as mães trabalhadoras, não apenas ex-escravas, deixariam seus filhos devido à necessidade de mão-deobra por parte da sociedade industrial e como alternativa de controle da mortalidade infantil. (FARIA, 1997)

De acordo com Filho (1997), em 1899, ocorrem às primeiras propostas de instituições pré-escolares quando funda-se o Instituto da Proteção e Assistência à Infância do Rio de Janeiro e inaugura-se a creche da Companhia de Fiação e Tecido Corcovado- RJ, mas antes desta data já estava em funcionamento dois Jardins de Infância de origem froebeliana, um no Rio de Janeiro, criado em 1875, no Colégio Menezes Vieira, e outro em São Paulo, na Escola Americana, em 
1877. Enquanto que no setor privado, em São Paulo, em 1896, é criado o Jardim de Infância da escola Caetano de Campos.

A creche inicialmente é vista como um mal necessário e as mães trabalhadoras como sendo responsáveis pelo abandono do lar e filhos, pois às mulheres das classes abastadas destinava-se a maternidade enquanto que às pobres, o trabalho. As entidades de filantropia, nesse momento apoiam o Estado na busca por realizar os atendimentos sociais aos abandonados.

Esse apoio configurou-se num estigma que perdurou por tempos, pois aqueles que não conseguiam conquistar a cidadania recebiam ajuda dos órgãos filantrópicos parceiros do Estado, mas se caracterizavam como indigentes, não cidadãos. Com estes, a preocupação principal era a de alimentar, cuidar da higiene e da segurança física, sendo pouco valorizado um trabalho orientado à educação e ao desenvolvimento intelectual e afetivo das crianças. (OLIVEIRA, 2011, p.100-101)

Com o passar do tempo, houve mais investidas na creche e o público-alvo passou a ser não apenas as mulheres trabalhadoras estigmatizadas como pobres, mas também mulheres que passaram a ocupar cargos na sociedade por conta da transformação do sistema econômico em vigor, o capitalismo. Com a virada de século (segunda metade do século XX), houve alterações na economia que refletiram na sociedade e no pensamento coletivo e, parte delas ocorreu no campo educacional. Esse avanço assegurou leis, normas e diretrizes que compreendem a Educação Infantil como direito da criança.

Desse conjunto, a Lei $\mathrm{n}^{\circ} 4024 / 61$ assegurou algumas perspectivas no que refere aos jardins de infância e à sua inclusão no sistema de ensino.

Art. 23 - A educação pré-primária destina-se aos menores de até 7 anos, e se ministra em escolas maternais ou jardins de infância,

Art. 24- As empresas que tenham ao seu serviço mães de menores de sete anos serão estimuladas a organizar e manter, por iniciativa própria ou em cooperação com os poderes públicos, instituições de educação pré-primária. (BRASIL, 1964)

Essa legislação reforça a percepção da transformação da sociedade e a preocupação com as crianças pequenas, o que até então não era tão evidente. Esse quadro reflete o contexto político ditatorial da época, o qual, de fato, teve reflexos na educação.

Percebeu-se que, com o passar do tempo a creche devia ser reconhecida como instituição educacional, não apenas como lugar para assistir às crianças 
provenientes das camadas populares mais baixas, mas como local de cunho educativo. Também a pré-escola passa a ser entendida não só como espaço de preparação para a escola, mas espaço de direito à educação como promoção da cultura.

Nessa perspectiva instaura-se um movimento político em prol das proles, quando ocorrem, dentre outras, as próprias iniciativas das mães em busca da democracia e a favor do aumento do atendimento, especialmente, nas creches. Em 1988, essas inciativas se refletem no texto da Constituição onde a educação é definida como direito da criança, da família e dever do estado. No texto constitucional, em seu artigo 208, inciso IV e art. 227, esse dever é explicitado.

Art. 208. O dever do estado com a educação será efetivado mediante a garantia de: IV. Atendimento em creches e pré-escolas às crianças de 0 a 6 anos de idade. (Constituição, 1988).

Art. 227. É dever da família, da sociedade e do Estado assegurar à criança e ao adolescente, com absoluta prioridade, o direito à vida, à saúde, à alimentação, à educação, ao lazer, à profissionalização, à cultura, à dignidade, ao respeito, à liberdade e a convivência familiar e comunitária, além de colocá-los a salvo de toda forma de negligência, discriminação, exploração, violência, crueldade e opressão. (CONSTITUIÇÃO FEDERAL, 1988)

A Constituição representa uma valiosa contribuição na garantia dos direitos das crianças e adolescentes, por ser fruto de um grande movimento de discussões e participação popular, no período de transição de regime autoritário para democracia. A Constituição se apresenta como um marco histórico, pois afirma os direitos da criança no Brasil e o dever do Estado a ser cumprido nos sistemas de ensino. A educação infantil, que até então era direito dos filhos de mães trabalhadoras regulamentado pela CLT, 1937, passa, com a Constituição, a ser direito de todas as crianças. (CORSINO, 2011, p.19)

A partir dessas mudanças houve um avanço nas políticas em favor da educação das crianças pequenas como a elaboração de um estatuto que assegure seus direitos e deveres, o Estatuto da Criança e do Adolescente aprovado pela lei 8.069/90, a partir da Constituição que regulamenta e reconhece no artigo 227 a criança como cidadã, sujeito de direitos. E nessa mesma perspectiva, no ano de 1994, o MEC propõe a formulação de uma Política Nacional de Educação. (FILHO LEITE, 2001).

Este documento trouxe uma nova perspectiva para a educação das crianças, no qual foram contempladas a expansão da oferta de vagas para as 
crianças de 0 a 6 anos $^{1}$ como também o fortalecimento da concepção de educação e cuidado como aspecto indissociável das ações. (Política Nacional de Educação Infantil pelo direito das crianças de zero a seis anos à educação, 2006).

Na década de 90, a Coordenação de Educação Infantil da Secretaria de Educação do MEC desenvolveu encontros, pesquisas e publicações, visando uma política que garantisse o direito das crianças até 6 anos a uma educação de qualidade. Esse movimento preparou o ambiente para a aprovação da Lei de Diretrizes e Bases da Educação Nacional, no 9394/96 (OLIVEIRA 2011, p.117) que contempla três artigos importantes que tratam da educação infantil.

Os artigos 29 e 30 que trata da organização e finalidade da educação infantil como primeira etapa da Educação Básica.

Art. 29. A educação infantil, primeira etapa da educação básica, tem como finalidade o desenvolvimento integral da criança de até 5 (cinco) anos, em seus aspectos físico, psicológico, intelectual e social, complementando a ação da família e da comunidade ${ }^{2}$

Art. 30. A educação infantil será oferecida em:

I - creches, ou entidades equivalentes, para crianças de até três anos de idade;

II - pré-escolas, para as crianças de quatro a seis anos de idade.

II - pré-escolas, para as crianças de 4 (quatro) a 5 (cinco) anos de idade. ${ }^{3}$

O artigo 31 aborda a organização do tempo, controle da freqüência e expedição de documentos bem como uma das principais questões no que tange às instituições educativas de modo geral, a avaliação, enfatizando o caráter formativo.

Art. 31. A educação infantil será organizada de acordo com as seguintes regras comuns: ${ }^{4}$

I - avaliação mediante acompanhamento e registro do desenvolvimento das crianças, sem o objetivo de promoção, mesmo para o acesso ao ensino fundamental; ${ }^{5}$

II - carga horária mínima anual de 800 (oitocentas) horas, distribuída por um mínimo de 200 (duzentos) dias de trabalho educacional;

III - atendimento à criança de, no mínimo, 4 (quatro) horas diárias para o turno parcial e de 7 (sete) horas para a jornada integral;

IV - controle de frequência pela instituição de educação pré-escolar, exigida a frequência mínima de $60 \%$ (sessenta por cento) do total de horas;

$\mathrm{V}$ - expedição de documentação que permita atestar os processos de desenvolvimento e aprendizagem da criança.

Esses artigos tratam da organização da educação infantil e, reafirmam a

\footnotetext{
${ }^{1}$ A idade de transição para o Ensino Fundamental foi alterada a partir da Lei $\mathrm{n}^{\mathrm{o}}$ 11276/2006 quando o Ensino Fundamental foi ampliado para nove anos de escolaridade.

2 (Redação dada pela Lei $n^{\circ} 12.796$, de 2013)

3 (Redação dada pela Lei $n^{\circ} 12.796$, de 2013)

4 (Redação dada pela Lei $n^{\circ} 12.796$, de 2013)

5 (Redação dada pela Lei $n^{\circ} 12.796$, de 2013)
} 
oferta de vagas nas instituições educativas para crianças com menos de 6 anos. $\mathrm{O}$ artigo 30 reforça a concepção da educação infantil para crianças de 0 a 3 anos e a sua oferta não sendo um benefício para as crianças pobres. Outro avanço neste artigo foi o de definir a avaliação sem objetivo de promoção. (FILHO, LEITE 2001, p.37).

Nesse sentido, a LDB estabelece a educação infantil como etapa inicial da educação básica, traçando um novo olhar para creches e pré-escolas, desmistificando tudo aquilo que foi construído historicamente com relação à questão de assistencialismo.

Outro marco na história da educação infantil ocorreu no ano de 1998, quando o Referencial Curricular Nacional para a Educação Infantil compondo um conjunto de três volumes foi elaborado e enviado às escolas de todo o país. Este documento que tem a proposta de ser uma referência para as práticas pedagógicas foi publicado pelo MEC e contemplava concepções acerca do desenvolvimento, da cognição e da linguagem, modificando as propostas pedagógicas para esta área.

Em caráter mandatório, em 1999 foi aprovado o Parecer 0022/98 que estabelece as Diretrizes Curriculares Nacionais para a Educação Infantil - DCNEI. Este documento partiu das críticas às políticas públicas para a infância historicamente construídas no país, e defende um novo paradigma de atendimento com base na Constituição de 1988, como um direito social, não apenas para filhos de trabalhadores, mas como direito da criança. (OLIVEIRA, 2011. p.119).

Pode se afirmar que a Educação Infantil, enquanto primeira etapa da Educação Básica se fortalece com a aprovação do Plano Nacional de Educação (BRASIL, 2001) que prevê padrões mínimos de infraestrutura para as instituições de Educação Infantil além das metas de expansão do atendimento para creches e pré-escolas em nível nacional.

No ano de 2006 foram publicados os Parâmetros Nacionais de Qualidade para a Educação Infantil com dois volumes, este documento tem referências de qualidade para a Educação Infantil a serem utilizadas pelos sistemas educacionais, por creches, pré-escolas e centros de Educação Infantil.

Acompanhando as mudanças nas políticas educacionais e as demandas da área, em 2009 foi estabelecida uma revisão das DCNEIs e de acordo com Oliveira, (2011. p.120) a aprovação das novas Diretrizes Curriculares Nacionais para a Educação Infantil (Parecer CNE/ CEB n 20/09 e Resolução 05/09) reforça 
a proposta pedagógica com objetivo de promover o desenvolvimento integral das crianças de zero a cinco anos de idade.

O novo documento enfatiza que o centro do planejamento pedagógico na Educação Infantil é a criança, com práticas cujos eixos são as brincadeiras e as interações. Estas Diretrizes juntamente com as Diretrizes Curriculares Nacionais da Educação Básica irão orientar as políticas públicas na área e a elaboração, o planejamento, a execução e avaliação de propostas pedagógicas e curriculares. (Parecer CNE/ CEB nº 20/09 e Resolução 05/09).

Este foi um breve histórico da educação infantil no Brasil por considerarmos necessário o seu conhecimento para o objeto de estudo do presente trabalho, a proposta pedagógica das instituições de educação infantil.

\section{2}

\section{A proposta pedagógica}

Ao ser elevada à primeira etapa da educação básica, a educação infantil, oferecida em creches às crianças de 0 a 3 anos e pré-escolas às crianças de 4 e 5 anos as instituições de atendimento passam a ser definidas enquanto espaços educativos, sob a responsabilidade dos governos municipais e assim estão submetidas ao estabelecido no artigo 12, Inciso I, da Lei de Diretrizes e Bases da Educação Nacional que determina que os estabelecimentos de ensino, respeitadas as normas comuns e as do seu sistema de ensino, terão a incumbência de elaborar e executar sua proposta pedagógica.

Como podemos definir o que seja a proposta pedagógica de uma instituição? Seria a linha de currículo que a mesma institui? Para responder esses e alguns questionamentos sobre a proposta pedagógica, buscamos os estudos de Veiga (1998) e Kramer e Kishimoto (2002).

De acordo com Kramer (2002), não há diferença conceitual entre currículo e proposta pedagógica. Tanto o currículo como a proposta pedagógica reúnem tanto as bases teóricas quanto as diretrizes práticas nela fundamentadas, bem como aspectos de natureza técnica que viabilizam sua concretização. A autora afirma que a proposta pedagógica é um caminho, que nasce de uma realidade que pergunta e é também busca de uma resposta, é diálogo.

Kishimoto define currículo como "explicitação de intenções que dirigem a 
organização da escola visando colocar em prática experiências de aprendizagem consideradas relevantes para crianças e seus pais"; programa como "delineamento de linhas de trabalho que pode ocorrer no plano mais geral (governamental ou institucional)" e proposta pedagógica como "explicitação de qualquer orientação presente na escola ou rede, não implicando necessariamente o detalhamento total da mesma." Entendendo experiências de aprendizagem como "a interação entre aluno e as condições exteriores do ambiente a que ele pode reagir" (KISHIMOTO 1994, apud KRAMER, 2002)

Veiga (1999) afirma que a proposta pedagógica relaciona-se à organização da sala de aula e outras atividades pedagógicas e administrativas e aponta um rumo, uma direção, um sentido explícito para um compromisso estabelecido coletivamente, buscando eliminar as relações competitivas, corporativas e autoritárias, rompendo com a rotina do mando pessoal e racionalizado da burocracia e permitindo as relações horizontais no interior da escola (p.13).

Portanto, a proposta pedagógica, ou projeto pedagógico, como definida pela DCNEs, parecer CEB 20/2009, é o plano orientador das ações da instituição e define as metas que se pretende para o desenvolvimento dos meninos e meninas que nela são educados e cuidados, as aprendizagens que se quer promovidas. A instituição executa e organiza seu currículo englobando as experiências vivenciadas pela criança, este deve ser concebido como um conjunto de práticas que busca articular as experiências e os saberes das crianças como os conhecimentos que fazem parte do patrimônio cultural, artístico, cientifico e tecnológico.

Nunes (2009) pontua que, para que a proposta atinja seu objetivo é necessário olhar para a criança e nos questionar como as entendemos e suas culturas infantis e como nos relacionamos com essas diferenças.

É importante que cada instituição organize a estrutura de sua proposta, pois cada proposta pedagógica tem sua história como pano de fundo, o contexto sociocultural no qual a instituição se insere, a concepção que norteia a ação educativa com suas qualidades e objetivos do trabalho que será desenvolvido com as crianças. (Dias e Faria, 2011)

\section{3}

\section{E quem faz a proposta?}

A gestão democrática da proposta curricular deve contar na sua elaboração, 
acompanhamento e avaliação, com a participação coletiva de professoras e professores, demais profissionais da instituição, famílias, comunidade e das crianças, sempre que possível e à sua maneira, define o Parecer 020/2009.

De acordo com a LDB, a elaboração da proposta é uma ação conjunto de todos os integrantes da instituição bem como uma das incumbências do professor no exercício de sua profissão. Art. 13. Os docentes incumbir-se-ão de:

I - participar da elaboração da proposta pedagógica do estabelecimento de ensino;

II - elaborar e cumprir plano de trabalho, segundo a proposta pedagógica do estabelecimento de ensino. (BRASIL, 1996)

Incumbidos dessa responsabilidade, os professores tem diante de si, numa proposta de gestão democrática, a oportunidade de imprimir no documento que identifica a instituição suas marcas bem como as das crianças, visto o seu contato direto com elas. Para Corsino (2009) existem alguns aspectos importantes a serem considerados tanto na elaboração quanto na avaliação de propostas pedagógicas para a educação infantil, nesse sentido destaca que,

...os profissionais da educação devem se perguntar sobre suas responsabilidades, analisando como compreendem seus trabalhos, a quem desejam educar e como deve ser a organização e a manutenção desse espaço para que a proposta coletiva possa ser construída (CORSINO, 2009, p. 42).

O próximo capítulo traz alguns pontos sobre as Diretrizes Curriculares Nacionais com a finalidade de fundamentar a reflexão sobre a função da proposta pedagógica. 


\title{
3
}

\section{A criança e a educação infantil}

O trabalho cotidiano das instituições de Educação Infantil tem a sua disposição um conjunto de documentos orientadores das práticas a serem desenvolvidas a saber - Parâmetros de Qualidade, Parâmetros de Infraestrutura, Indicadores de Qualidade, dentre outros, todavia, para além desse conjunto de orientações, as Diretrizes Curriculares Nacionais para a Educação Infantil, de caráter mandatório, orientam a formulação de políticas, incluindo a de formação de professores e demais profissionais da Educação, e também o planejamento, desenvolvimento e avaliação pelas unidades de seu Projeto Político-Pedagógico e servem para informar as famílias das crianças matriculadas na Educação Infantil sobre as perspectivas de trabalho pedagógico que podem ocorrer.

As DCNEIs apresentam a Educação Infantil com uma identidade própria, com isso todo movimento em relação a normas, currículo e propostas pedagógicas deve estar de acordo com essa identidade. Elas também apresentam questões legais no que diz respeito ao dever do Estado e de instituições públicas ou privadas, estabelecendo a faixa etária, o período de funcionamento que deve ser regulado e supervisionado por orgãos competentes do sistema de ensino e submetido a controle social, a oferta de vagas próximas às residências, a idade de corte para efetuar a matrícula e a idade para ingresso no ensino fundamental.

\begin{abstract}
A aprovação de novas diretrizes curriculares nacionais para a educação infantil (parecer CNE/CEB no 20/09 e Resolução CNE/CEB no 05/09) reforçou que a proposta pedagógica das instituições de Educação Infantil deve ter como objetivo principal promover o desenvolvimento integral das crianças de zero a cinco anos de idade, garantindo a cada uma delas o acesso a processos de construção de conhecimentos e a aprendizagem de diferentes linguagens, assim como o direito à proteção, à saúde, à liberdade, ao respeito, à dignidade, à brincadeira, à convivência e interação com outras crianças. (OLIVEIRA, 2011, p. 120-121)
\end{abstract}

Com o objetivo de dialogar com esse documento, no presente capítulo destacaremos alguns pontos e artigos a fim de orientar a análise da proposta pedagógica de uma instituição educacional que será desenvolvida no capítulo 4 .

\section{1}

\section{Educação infantil: espaço de construção de conhecimentos}

Para início de conversa, considero oportuno destacar a concepção de 
Educação Infantil impressa nesse importante documento:

Art. $5^{\circ}$ A Educação Infantil, primeira etapa da Educação Básica, é oferecida em creches e pré-escolas, as quais se caracterizam como espaços institucionais não domésticos que constituem estabelecimentos educacionais públicos ou privados que educam e cuidam de crianças de 0 a 5 anos de idade no período diurno, em jornada integral ou parcial, regulados e supervisionados por órgão competente do sistema de ensino e submetidos a controle social.

$\S 6^{\circ}$ É considerada Educação Infantil em tempo parcial, a jornada de, no mínimo, quatro horas diárias e, em tempo integral, a jornada com duração igual ou superior a sete horas diárias, compreendendo o tempo total que a criança permanece na instituição. (BRASIL, 2009)

Destaco que é ressaltado o caráter institucional dessa etapa educativa superando a visão assistencialista e imprimindo a legitimidade do direito à educação de todas as crianças independente de sua classe social e, sendo compreendida como espaço educacional impõe a necessária formulação de um currículo que norteará a dinâmica ensino aprendizagem nesse contexto e assim,

Art. $3^{\circ} \mathrm{O}$ currículo da Educação Infantil é concebido como um conjunto de práticas que buscam articular as experiências e os saberes das crianças com os conhecimentos que fazem parte do patrimônio cultural, artístico, ambiental, científico e tecnológico, de modo a promover o desenvolvimento integral de crianças de 0 a 5 anos de idade. (BRASIL, 2009)

É de suma importância assinalar que a proposta de currículo apresentada no documento, foge ao escopo conteudista que caracteriza as demais etapas da educação básica e imprime a identidade da Educação Infantil como espaço de práticas que objetiva o desenvolvimento integral das crianças. $\mathrm{O}$ artigo se amplia quando assinala o reconhecimento das experiências e saberes das crianças como conhecimentos. Tal definição aponta para uma forma de conceber a criança como sujeito ativo em seu processo de aprendizagem. Tal concepção delineia as orientações para a construção da proposta pedagógica.

Art. $4^{\circ}$ As propostas pedagógicas da Educação Infantil deverão considerar que a criança, centro do planejamento curricular, é sujeito histórico e de direitos que, nas interações, relações e práticas cotidianas que vivencia, constrói sua identidade pessoal e coletiva, brinca, imagina, fantasia, deseja, aprende, observa, experimenta, narra, questiona e constrói sentidos sobre a natureza e a sociedade, produzindo cultura. (BRASIL, 2009)

Portanto, o espaço da educação infantil, é o lugar institucional cuja função de educar e cuidar acontece de forma legítima resguardada em lei como direito da criança. O currículo deste seguimento deve ser construído e pensando no sujeito enquanto autor, que possuem experiências que deverão ser articuladas com os saberes que fazem parte do patrimônio cultural entre outros conhecimentos. Vale 
ressaltar que, por trás de um documento há uma concepção teórica que embasa a corrente escolhida e esta vai ter toda relação com o entendimento desse currículo. Kramer (2005) na sua publicação "com a pré-escola nas mãos - uma alternativa curricular para educação infantil" afirma que toda a proposta deve ser orientada por pressupostos teóricos que explicitam as concepções de criança, de educação e de sociedade. A autora sugere que o currículo não é um programa a ser seguido pelas instituições de educação infantil; ela propõe um currículo que veja a criança como um sujeito em toda a sua totalidade (afetivo, social, político, inteligente, ativo). Afinal, somente com essa consciência é possível ter qualidade no trabalho com as crianças. Então, é nesse cerco que as propostas curriculares serão construídas e embasadas.

\section{2}

\section{Educação infantil: espaço de formação de princípios}

De acordo com o documento, alguns princípios devem ser articulados com a proposta pedagógica das Instituções de Educação Infantil (Resolução CNE/CEB $n^{\circ}$ 05/09, artigo $\left.6^{\circ}\right)$. São eles:

Éticos: da autonomia, da responsabilidade, da solidariedade e do respeito ao bem comum, ao meio ambiente $\mathrm{e}$ às diferentes culturas, identidade $\mathrm{e}$ singularidades.

Políticos: dos direitos de cidadania. Do exercício da criticidade e do respeito à ordem democrática.

Estéticos: da sensibilidade, criatividades, da ludicidade e da liberdade de expressão nas diferentes manifestações artísticas e culturais. (BRASIL, 2009)

Partindo de uma concepção da criança como sujeito histórico tais princípios apontam para a formação de cidadãos humanos, responsáveis e comprometidos.

... os princípios éticos serão estabelecidos assegurando às crianças a manifestação de seus interesses, desejos e curiosidades ao participar das práticas educativas, valorizando as produções individuais e coletivas, apoiando a conquista pelas crianças de autonomia na escolha de brincadeiras e de atividades além de realização de cuidados pessoais. (OLIVEIRA, 2010, p.8).

Nessa perspectiva, os princípios políticos são indispensáveis numa proposta de educar para a cidadania e, implica em um movimento contínuo de avaliação e planejamento das práticas educativas, entendendo que educar para a cidadania é criar contextos onde as crianças possam expressar seus sentimentos, opinar, promovendo a formação participativa e crítica das mesmas além de garantir experiências relevantes de aprendizagem a todas as crianças.

Educar para a cidadania envolve a formação de atitudes de solidariedade para com 
os outros, particularmente com aqueles em dificuldade de superação de atitudes egoístas; implica fazer gestos de cortesia, preservar o coletivo, responsabilizar-se pelas próprias ações e discutir aspectos éticos envolvidos em determinada situação. Inclui, para cada criança, poder se expressar e respeitar a expressão do outro em relação a sentimentos, ideias, costumes, preferências, ser aceita em suas caracerísticas físicas e morais, receber demonstração de interesse quando não comparece à creche ou pré-escola, demonstrar interesse em saber as rezões da ausência de outra criança e criar formas ão violentas de solução de conflitos. (OLIVEIRA, 2011, p.52-53)

Os princípios estéticos por sua vez, também serão desenvolvidos nas práticas cotidianas à medida que, seja garantida a participação das crianças em diversificadas experiências, organizadas em um cotidiano de situações agradáveis que estimulem a criticidades, o trabalho coletivo e em pequenos grupos, bem como individuais possibilitando a apropriação de diferentes linguagens e saberes.

Contribuir para a formação da sensibilidade das crianças significa incentivar e criar oportunidades para que elas se expressem, ampliem e enriqueçam suas experiências, aumentando suas possibilidades de interlocução e o entendimento da realidasde que as cerca ..." A formação da sensibilidade não está restrita ao espaço escola; ela se dá na vida todos os dias, na relação com os objetos e com as pessoas, na relação com o mundo que nos cerca e, a cada momento, transforma-nos e coloca-nos em contínuo movimento."... Ao considerarmos a faixa etária das crianças que frequentam instituições de educação infantil (o a 6 anos), contribuir para a formação da sensibilidade significa incentivar e criar oportuinidades para que elas se espressem com a vivacidade e possam desenvolver ampliar e enriquecer suas experiências sensíveis, aumentando as redes de entendimento e de significação do mundo. (DIAS, 1999, p. 176-177)

A proposta pedagógica deve articular os três princípios fundamentais apontados nas DCNEs, como vimos eles dissertam que a criança precisa de ser vista enquanto cidadão de diretos. Para que esses princípios sejam cumpridos o planejamento deve ser flexível, visto que, cada criança tem o seu tempo e haver espaço de escuta possibilitando contextos onde as crianças possam expressar suas culturas, manifestação dos seu interesses e desejos. Isso só é possível quando há o movimento de avaliação das práticas contínua, observando se ela está sendo realizada para cumprir horário ou construção de conhecimento.

\section{3}

\section{Educação infantil: espaço de função sociopolítica e pedagógica}

As DCNEIs (Resolução CNE/CEB n ${ }^{\circ}$ 05/09 artigo $7^{\circ}$ ) consideram que a função da proposta pedagógica das instituições de Educação Infantil deve garantir que elas cumpram plenamente sua função sociopolítica e pedagógica, oferecendo 
condições e recursos para que as crianças usufruam dos seus direitos civis, humanos e sociais e nesse sentido:

Art $7^{\circ}$ Assumir a responsabilidade de compartilhar e complementar a educação e cuidado das crianças com as famílias.

Possibilitar tanto a convivência entre crianças e entre adultos e crianças quanto a ampliação de saberes e conhecimentos de diferentes naturezas.

Promover a igualdade de oportunidades educacionais entre as crianças de diferentes classes socias no que se refere ao acesso a bens culturais e às possibilidades de vivência da infância.

Construir novas formas de sociabilidade e de subjetividade comprometidas com a ludicidade, a democracia, a sustentabilidade do planeta e com o rompimento de relações de dominação etária, socioeconômica, étnico-racial, de gênero, regional, linguística e religiosa. (BRASIL, 2009)

Neste artigo foram contemplados o direitos civis e sociais da criança, dentre eles, a educação que, de acordo com a Constituição Federal de 1988: “é direito de todos e dever do Estado e da família e, será promovida e incentivada com a colaboração da sociedade, visando o pleno desenvolvimento da pessoa, seu preparo para o exercício da cidadania e sua qualificação para o trabalho". (BRASIL, 1988 artigo 205).

No artigo $8^{\circ}$, o documento disserta sobre o objetivo das propostas pedagógicas de garantir à criança o acesso a processos de apropriação, renovação e articulação de conhecimentos e aprendizagens de diferentes linguagens, assim como o direito à proteção, à saúde, à liberdade, à confiança, ao respeito, à dignidade, à brincadeira, à convivência e à interação com outras crianças". (Resolução CNE/CEB $n^{\circ}$ 05/09). Nesse intuito, as propostas deverão prever condições de trabalho coletivo e organização de materiais, espaços e tempos de forma a assegurar a educação de modo integral, entendendo o cuidado como algo indissociável do processo educativo e, considerar a indivisibilidade e integralidade das dimensões expressivo-motora, afetiva, cognitiva, linguística, ética, estética e sociocultural da criança. Para tanto, ao planejar o currículo deve-se considerar as especificidades de cada faixa etária vendo a criança como uma pessoa inteira.

Segundo Guimarães,

De acordo com a legislação, educar e cuidar são ações indissociáveis e complementares no cotidiano da Educação Infantil. Delimitam o que é específico do trabalho com as crianças pequenas. No entanto, nas práticas cotidianas, contituem-se diversas formas de viver essas duas ações de modo segmentado. A ação de educar é compreendida como instruir e transmitir conhecimentos (ensinar as cores, os nomes dos objetos etc.), numa pespectiva de tutela da ação da criança e de sua compreensão do mundo. Cuidar é considerado como atender as demandas de sono , higiene e alimentação, proteger, ou "tomar conta" da criança, numa 
intenção disciplinadora. Muitas vezes, o cuidado assume dimensão higienista, com ênfase na preservação da saúde e no estabelecimento de normas e preceitos para prevenir doenças, garantir o asseio e a limpeza. A dissociação dessas duas ações e os limites na abrangência de seus sentidos provocam uma série de reflexões e estudos, no movimento de redirecionar as práticas, tendo em vista viver nas creches sem dicotomizar cuidado e educação. (GUIMARÃES, 2011, p. 37-38)

Considerada a indissociabilidade do educar e cuidar destaca-se também a necessária articulação com as famílias e a comunidade.

Q A participação da família, o repeito e a valorização das suas formas de organização, crenças e manifestações. Para que isso aconteça, a escola deve se organizar para que haja espaço para o diálogo e a escuta das famílias.

D Estabelecer uma relação efetiva com a comunidade local, reconhecer as especificidades etária, reconhecer os modos próprios de vida no campo, reconhecer as histórias e as culturas africanas, afro-brasileiras, bem como o combate ao racismo e à discriminação.

Como espaços de ensino/aprendizagem, faz-se necessária a organização e planejamento das práticas tendo em vista as especificidades e necessidades de todas as crianças, respeitando-as e assim,

口 Ofertar materiais e objetos diferentes para os bebês, crianças maiores, crianças com deficiência, transtornos globais de desenvolvimento e altas habilidades/superdotação, e as diversidades sociais, culturais, étnicoraciais e linguísticas das crianças, famílias e regiões.

o Considerar a relevância da brincadeira como atividade fundamental nessa fase do desenvolvimento, criar oportunidades para que essa prática aconteça diariamente.

口 Combater as discriminações de gênero, étnicos raciais, religiosas, racistas e sócio-econômicas.

Assim sendo, a função sociopolítica e pedagógica vai exigir das instituições de educação infantil a responsabilidade de compartilhar e complementação da educação e cuidado das crianças com as famílias. Essa relação atinge seu objetivo quando a escola e as famílias trabalham em parceria. A interação entre as crianças/ crianças e adultos possibilita o desenvolvimento novas aprendizagens são construídas no decorrer dessa mediação. Com isso, percebemos o papel principal que a proposta pedagógica confere, pois ela vai direcionar quais são objetivos a 
serem traçados e no planejamento das práticas eles estarão explícitos e desenvolvidos nas práticas cotidianas

\section{4}

\section{Educação infantil: espaço de brincadeiras e interações}

De acordo com Zilma Ramos de Oliveira, para garantir às crianças seu direito de viver a infância e se desenvolver, as creches e pré-escolas devem:

...organizar situações agradáveis, estimulantes, que ampliem as possibilidades infantis de cuidar de si e de outrem, de se expressar, comunicar e criar, de organizar pensamentos e ideias, de conviver, brincar e trabalhar em grupo, de ter iniciativa e buscar soluções para os problemas e conflitos que se apresentam às mais diferentes idades, desde muito tempo. O ambiente deve ser rico de experiências para exploração ativa e compartilhada por crianças e professores, que controem significações nos diálogos que estabelecem.(OLIVEIRA, 2010, p. 10)

Nesse sentido, o artigo $9^{\circ}$ da Resolução ressalta que as práticas pedagógicas que compõem a proposta curricular da Educação infantil devem ter como eixos norteadores as interações e a brincadeira e, estabelecer modos de integração de acordo com suas características, identidade institucional, escolhas coletivas e particularidades pedagógicas. Sendo assim, são relacionados 12 aspectos para orientar as experiências a serem desenvolvidas, a saber:

O Promover o conhecimento de si e do mundo por meio da ampliação de experiências sensoriais, expressivas, corporais que possibilitem movimentação ampla, expressão da individualidade e respeito pelos ritmos e desejos da criança;

Q Favorecer a imersão das crianças nas diferentes linguagens e o progressivo domínio por elas de vários gêneros e formas de expressão: gestual, verbal, plástica, dramática e musical;

Q Possibilitar às crianças viverem experiências de narrativas, de apreciação e interação com a linguagem oral e escrita, e convívio com diferentes suportes e gêneros textuais orais e escritos;

○ Recriar, em contextos significativos para as crianças, relações quantitativas, medidas, formas e orientações espaçotemporais;

Q Possibilitar situações de aprendizagem mediadas para a elaboração da autonomia das crianças nas ações de cuidado pessoal, auto-organização, saúde e bem-estar; 
Q Possibilitar vivências éticas e estéticas com outras crianças e grupos culturais, que alarguem seus padrões de referência e de identidades no diálogo e reconhecimento da diversidade;

- Incentivar a curiosidade, a exploração, o encantamento, o questionamento, a indagação e o conhecimento das crianças em relação ao mundo físico e social, ao tempo e à natureza;

Q Promover o relacionamento e a interação das crianças com diversificadas manifestações de música, artes plásticas e gráficas, cinema, fotografia, dança, teatro, poesia e literatura;

Q Promover a interação, o cuidado, a preservação e o conhecimento da biodiversidade e da sustentabilidade da vida na Terra, assim como o não disperdício dos recursos naturais;

- Propiciar a interação e o conhecimento pelas crianças das manifestações e tradições culturais brasileiras.

As indicativas apontadas tem o objetivo de criar situações de aprendizagem onde as crianças vivenciem experiências que as possibilite conhecer o mundo e a si mesmas, participando de atividades coletivas e individuais. Experiências que visem introduzir as crianças em práticas de criação e comunicação. As práticas pedagógicas da educação infantil estão alicerçadas no projeto pedagógico da instituição. O projeto pedagógico fundamenta e organiza o conhecimento contruído em meio às relações sociais no espaço da instituição que contribui para a construção da identidade das crianças. Portanto, as experiências e saberes que as crianças trazem junto com o conhecimento planejado pelas instituições através do patrimônio cultural, artístico, tecnológico e científico estruturam as práticas cotidianas nas instituições de Educação Infantil.

Finalmente, as DCNEIs vão mencionar a questão da avaliação na Educação Infantil a qual não pode ser instrumento de seleção, promoção ou classificação. (Resolução CNE/CEB nº5/09 artigo no n $^{\circ}$ ) A avaliação na Educação Infantil é compreendida como uma reflexão contínua do desenvolvimento de cada criança, esta pode ser realizada por meio de múltiplos registros sejam eles relatórios, fotografias, desenhos etc. Isso será possível através da observação sistemática do comportamento de cada criança, interações, brincadeiras e todo o processo de aprendizagem. 
Sintetizando, as DCNEIs apresentam a Educação Infantil com uma identidade própria e especificam que essa identidade é vista quando contemplamos a criança como um todo, ou seja, integralmente em todos os aspectos. É fundamental estimular esse desenvolvimento integral valorizando suas experiências trazidas e proporcionando novas experiências.

Feitas as considerações iniciais que servem como um norteador para os objetivos desse trabalho, no próximo capítulo, apresentaremos a proposta pedagógica de uma instituição para, em seguida analisar e refletir a perspectiva de criança e de Educação Infantil expressas nos documentos oficiais. 


\section{A proposta no cotidiano - espaço, rotina, brincadeiras e interações}

A Educação Infantil é a primeira etapa da Educação básica e, de acordo com a legislação em vigor é direito de todas as crianças independente de sua classe social. Em nosso país, o direito à educação de qualidade é garantido através do acesso à instituições educativas. Conforme as Diretrizes Curriculares Nacionais para a Educação Infantil (BRASIL, 2009), a proposta pedagógica dessas instituições será o instrumento que legitima a concepção de criança que vai nortear essa proposta educacional, visto que, esta deve ser dotada com sua identidade própria e estimulada para o seu desenvolvimento integral.

A partir do objetivo deste trabalho que é, desenvolver uma análise crítica de como ocorre essa proposta pedagógica articulada às práticas de ensino no cotidiano da educação infantil, no presente capítulo serão apresentados os resultados da investigação. A pesquisa foi desenvolvida a partir da observação do cotidiano de turmas da educação infantil. Para fundamentar essa análise nos apoiamos nas definições das Diretrizes Curriculares Nacionais para a Educação Infantil.

... a observação ocupa um lugar privilegiado nas novas abordagens de pesquisa educacional. Usada como o principal método de investigação ou associada a outras técnicas de coleta, a observação possibilita em contato pessoal e estreito do pesquisador com o fenômeno pesquisado, o que apresenta uma série de vantagens. (LÜDKE, ANDRÉ, 1986, p. 26)

Lüdke e André (1986) aponta ainda que a análise documental é pouco explorada no campo educacional, mas pode contribuir para uma coleta de dados na abordagem qualitativa. Estes podem ser qualquer material escrito, incluindo leis e regulamentos, normas, jornais, revistas, discursos e arquivos escolares. Os documentos constituem também uma fonte poderosa de onde podem ser retiradas evidencias que fundamentem afirmações e declarações do pesquisador.

Nessa perspectiva, para a análise da proposta e as observações projetamos alguns questionamentos com a finalidade de buscar possíveis respostas: Qual é a concepção de infância da escola? Como a escola compreende essa proposta pedagógica? Como essa proposta é desenvolvida? O planejamento semanal dialoga com a proposta pedagógica?

Kramer (2001) pontua que a proposta pedagógica deve expressar os valores 
que a constituem, e está articulada a realidade. Esta deve ser construída com a participação da comunidade, levando em conta suas necessidades, especificidades, realidade. Isso aponta que não tem como construir uma proposta única, tendo em vista que a realidade é múltipla e contraditória. A autora aponta que toda proposta precisa partir de uma concepção de infância como categoria social, compreendendo essa criança inserida na história e na cultura.

\section{1 \\ Qual escola é essa?}

A proposta pedagógica ora analisada é o documento de identidade de uma das escolas da rede privada do Rio de Janeiro e está localizada no Bairro de Jacarepaguá com matrículas nas etapas: Educação infantil, Ensino Fundamental e Ensino Médio.

Atendendo aos objetivos desse trabalho, selecionamos para a análise a proposta pedagógica da educação infantil.

Esse segmento é composto por: 02 (duas) turmas de maternal I - com faixa etária entre 2 (dois) e 3(três) anos, 04 (quatro) turmas de maternal II- com faixa etária entre 3 (três) e 4 (quatro) anos, 06 (seis) turmas de pré I- com faixa etária entre 4 (quatro) e 5 (cinco) anos e, 06 (seis) turmas de pré II- com faixa etária entre 5 (cinco) e 6 (seis) anos divididas em dois turnos.

A equipe da escola conta com um grupo de professores regentes e auxiliares, uma coordenadora pedagógica, uma orientadora educacional, um diretor e uma vice- diretora, além dos profissionais da limpeza e alimentação, terceirizados pela instituição.

O corpo docente é assim organizado: uma professora regente e duas professoras auxiliares para cada maternal e uma professora regente e outra professora auxiliar para cada turma da pré-escola.

O horário de funcionamento é de $7 \mathrm{~h} 30 \mathrm{~min}$ às $12 \mathrm{~h} 30 \mathrm{~min}$ no turno da manhã e, 12h30min às $17 \mathrm{~h} 30 \mathrm{~min}$, no turno da tarde.

A escola é uma das unidades de uma rede de ensino e iniciou seu funcionamento na unidade Jacarepaguá em 1999 onde oferece seus serviços à crianças de classe média alta.

A turma observada recebe crianças com a faixa etária de $2 / 3$ anos totalizando 20 crianças. 


\section{2}

\section{A proposta pedagógica da escola}

De acordo com o documento, a proposta pedagógica da instituição foi elaborada com a participação do Corpo Docente e Técnico, abordando finalidades, princípios, diretrizes, currículo e avaliação levando em consideração as características de seu alunado e os objetivos educacionais a que se propõe.

Conforme o documento, nessa instituição, a educação infantil tem por pilares os seguintes princípios:

a) Respeito à dignidade e aos direitos da criança considerando as diferenças individuais, sociais, econômicas, éticas, religiosos.

b) Direito ao brincar como forma particular de expressão do pensamento, integração e comunicação infantil.

c) Acesso aos bens socioculturais disponíveis, ampliando o desenvolvimento das capacidades relativas à expressão, comunicação, interação social, pensamento, ética e estética.

d) Socialização por meio de participação de inserção nas diversificas práticas sociais sem discriminação.

e) Conscientização da prática ecológica por meio de aulas de educação ambiental e de atitudes reflexivas no dia-a-dia.

O documento afirma ainda que é necessário observar a natureza da criança, compreendendo, conhecendo e reconhecendo o seu jeito particular de estar no mundo e que através das situações de cuidado, brincadeiras e aprendizagens será possível contribuir para o desenvolvimento das capacidades infantis e estes princípios podem ser concretizados na prática.

A filosofia da instituição consiste na formação integral do aluno, baseandose nos princípios de solidariedade humana e dignidade, oferecendo possibilidades para o desenvolvimento de suas capacidades intelectuais, bem como aquisição de vivências de caráter socioeducativo e cultural.

\subsection{1}

\section{Cuidar e educar}

A instituição compreende o cuidar como forma de valorização e auxílio ao desenvolvimento das capacidades da criança, sendo parte integrante da educação 
integrando vários campos de conhecimento e cooperação de profissionais de diferentes áreas. Ou seja, o cuidado perpassa pelo desenvolvimento integral da criança, envolvendo a dimensão afetiva dos cuidados biológicos dos corpos, como a quantidade da alimentação e dos cuidados com a saúde.

Pode se entender que cuidar não envolve só uma habilidade técnica, mas uma atenção, reflexão, contato e, levando em conta o componente emocional, cuidar envolve carinho, atenção ao outro. Ao mesmo tempo, apesar de cuidado relacionarse com reflexão, não se restringe ao campo da introspecção, mas implica também atitudes para com o outro, podendo dirigir-se a coisas ou pessoas; portanto, voltando para si e para o mundo. (GUIMARÃES, 2011, p.46 apud Montenegro, 2005)

A concepção de cuidado impressa no texto considera a criança enquanto sujeito integral sem dissociar suas relações corporais e emocionais, atento e sensíveis ao que ela sente e pensa sobre si e o mundo visando a ampliação de seu autoconhecimento e de suas habilidades possibilitando assim a autonomia.

\subsection{2}

\section{As brincadeiras e interações}

O brincar é compreendido como um momento em que as crianças constroem o conhecimento utilizando diferentes linguagens e as interações que estabelece com as outras crianças e adultos. Através do brincar, as crianças criam, repensam os acontecimentos de origem, assumem papéis e ao adotar outros papéis, na brincadeira, agem de maneira não literal, transferindo e substituindo o cotidiano por caraterísticas do papel assumido.

Através das brincadeiras, os professores podem observar e contribuir na visão dos processos de desenvolvimento das crianças em conjunto e de cada um individualmente, como também fazer intervenções de caráter educativo, emocional, social e cognitivo.

\subsection{3 \\ E o currículo}

Na organização do trabalho educativo deve-se levar em conta a escuta da criança e a compreensão do papel da experimentação e do erro na construção do conhecimento.

O currículo se organiza exclusivamente por atividades e utiliza metodologias que visam ao desenvolvimento dos processos cognitivos, afetivos, 
físicos e sociais, caraterísticos da faixa etária a que se destinam. Este é dividido por unidades de experiência, respeitando-se os interesses individuais e os ritmos diversificados dos alunos.

As unidades de experiência podem ser propostas pelas professoras, detectadas no grupo ou sugeridas pelas crianças. Elas podem ser cíclicas ou determinadas a partir de interesses imediatos. As unidades cíclicas derivam de festas, eventos ou comemorações. O planejamento das unidades de experiência favorecerá as áreas do conhecimento, integrando-as.

Segundo o texto do documento, a criança construirá seu conhecimento e o colégio procurará dar-lhe instrumentos necessários para que consiga perceber com clareza o mundo em que vive.

O documento não disserta qual é especificamente a fundamentação teórica utilizada para construir a proposta, mas ao inquirir a orientação pedagógica quanto a essa questão, a mesma informou que a escola adota a linha sociointeracionista. A proposta está sofrendo alterações.

Quanto ao planejamento semanal, as professoras da educação infantil se encontram 1 (uma) vez por semana para planejar as atividades baseadas no plano curricular.

\section{3}

\section{Analisando a proposta}

$\mathrm{Na}$ leitura da proposta é possível perceber a impressão das vozes dos participantes que a escreveram e apresenta diretrizes que resultam de suas experiências anteriores, além de explicitar que a base deste instrumento foi construída a partir das Diretrizes Curriculares Nacionais para a Educação Infantil (Brasil, 2009).

A concepção de criança/ infância apontada é definida a partir da ótica de que estes são sujeitos que possuem uma história e que a constrói a partir das vivências e experiências de interações internas e externas.

O cuidado é mencionado como tarefa primordial no processo educativo, pois o desenvolvimento integral da criança depende dos cuidados nas esferas emocionais e afetivas assim como é também relacionado à saúde.

O parecer das DCNEIs (parecer CEB 20/2009) pontua o cuidado como algo indissociável do educar. As práticas envolvidas nos atos de alimentar-se, tomar 
banho, trocar fraldas entre outras, não são apenas práticas que respeitam o direito da criança de ser bem atendida nesses aspectos, mas práticas que permitem apropriação e conhecimentos por meio das experiências corporais.

Podemos afirmar que o texto da proposta supera a perspectiva que orienta o trabalho de algumas instituições educativas onde,

A ação de educar é compreendida como instruir transmitir conhecimentos (ensinar as cores, o nomes dos objetos etc.), numa perspectiva de tutela da ação da criança e de sua compreensão do mundo. Cuidar é considerado como atender e às demandas de sono, higiene e alimentação, proteger, ou "tomar conta" da criança, numa intenção disciplinadora. (GUIMARÃES, 2011, p. 37-38)

Outro importante aspecto a ser destacado é a relevância das brincadeiras e interações como eixos do desenvolvimento da criança. No documento o brincar é, de fato, o eixo do trabalho pois "vai permear toda construção do conhecimento do sujeito, visto que, através das brincadeiras acontecem as interações”.

Tal compreensão vai ao encontro das DCNEIs (parecer CEB 20/2009) quando aponta que o brincar dá à criança oportunidade de imitar o conhecimento e para construir o novo, é nesse cotidiano que as crianças vão aprender como agir ou resistir aos valores e normas da cultura de seu ambiente.

\section{4}

\section{E na prática, como é que acontece?}

A leitura do documento é o primeiro passo na busca por conhecer a concepção de criança, de educação infantil, do brincar e das interações no cotidiano da instituição. Buscando investigar se o texto sistematizado se concretiza nas práticas, consideramos oportuno observar o cotidiano.

A turma do maternal I tem por projeto detonador dos trabalhos "A turma da Mônica” de Mauricio de Sousa, mas dialoga com o tema proposto pela ONU que é o Ano Nacional das Leguminosas. O plano de curso foi traçado com seus objetivos e conteúdos baseados nessa temática.

A educação infantil tem uma grade curricular extra (turmas de Maternal I, Maternal II e Pré I) com Educação Ambiental, Psicomotricidade, Música e Alemão. Nas turmas de Pré II, as aulas extras são de artes.

\section{Observação 1}

A observação foi realizada na aula de Educação Ambiental realizada com a 
turma do maternal. A aula é ministrada por um professor com formação em biologia e acontece a cada quinze dias com duração de 30 minutos horas no espaço da sala de aula.

O professor fez a introdução explicando o feijão e as leguminosas, para isso utilizou a história do João e o pé de feijão, em formato de desenho animado "As aventuras de Miau: João e o pé de feijão". Em seguida, desenvolveu um debate com as crianças acerca da história, que foi um momento rico, pois cada um pode trazer sua interpretação e leitura. Nesse momento houve espaço para trocas, pois através dessa roda de conversa e a exploração do feijão enquanto leguminosa as crianças levantam seus questionamentos.

- "Mas o feijão não é pretinho"? "Eu nunca comi feijão branco", nesse momento, as vivencias dos outros são pontes para mediar um novo conhecimento. Tudo parece uma grande brincadeira, pois o professor traz alguns grãos e eles observam, tocam e se relacionam com essa nova percepção. Como o planejamento dialoga com as disciplinas extras, ao retornarem para a sala, a professora regente segue o tema e trabalha a germinação onde novas vivências são possíveis enriquecendo o tema.

O processo educativo, ao proporcionar o exercício do diálogo horizontal entre seus diferentes sujeitos, onde é permitido dizer sem medo ou castração o que se pensa e o que se sente, preenche de sentido os seus reais objetivos. (ANGELO, 2014. p. 58)

\section{Observação 2}

Em outro dia de observação as crianças estavam na sala de aula em roda, a rotina cotidiana é apresentada. A professora conversa com as crianças sobre o feijão e faz uma releitura da história a partir do reconto da mesma, feita pelas crianças. A próxima atividade foi germinar esse feijão.

Cada criança recebeu um copo descartável com algodão e alguns grãos do feijão para observar o seu crescimento. O foco era trabalhar o crescimento do feijão e, esse cuidado com o alimento foi realizado durante uma semana. As crianças puderam acompanhar o crescimento da leguminosa e cuidar do seu desenvolvimento regando e levando para passear pela escola.

Por outro lado, na aula seguinte de educação ambiental, o professor levou as crianças ao canteiro onde é feita a horta e cada criança plantou, na terra, alguns grãos de feijão onde também podiam ver o crescimento do feijão sempre que passam pela horta, além de regar contribuindo para o seu crescimento bem como 
comparar esse processo nas duas experiências.

Outra atividade foi gerada em torno da experiência com o feijão. O colégio realiza anualmente uma de mostra de ciências e artes. A experiência com o feijão e as leguminosas estava presente na mostra e as crianças, além da exposição e explicação tiveram a possibilidade de comer o feijão preparado de várias maneiras, pois foi feita a experimentação do feijão tropeiro, tutu de feijão, doce de feijão e sopa de feijão branco.

A partir das observações, podemos considerar que a proposta da instituição foi construída pensando na criança enquanto sujeito que constrói o conhecimento a partir das experiências que vivencia e das possíveis interações com o outro, o ambiente, os objetos e seus pares.

Outro importante aspecto a ser destacado é a escuta da criança que é tomada como disparadora para consolidar na prática o planejamento que acolhe as diferentes culturas.

Essas considerações apontam para um cotidiano marcado por situações onde as crianças são encorajadas a falar sobre o que vivem, viram, tocaram, experimentaram, sentiram e pensaram. Através da linguagem há a organização do pensamento, que por sua vez organiza a fala. É nessa perspectiva que o adulto possui um papel fundamental, pois ele vai proporcionar experiências diversificadas e enriquecedoras, com a finalidade de fortalecer o desenvolvimento das capacidades das crianças. É a partir dessa troca entre o sujeito e o meio. Do contato com o corpo, ambiente e as interações das crianças que as capacidades afetivas, emocionais, sociais e cognitivas serão desenvolvidas.

Considerando que o meio humano é histórico, Wallon entende o desenvolvimento como uma sucessão de modos de relação com diferentes meios ambientes, decorrentes dos meios funcionais (ou recursos) de que, em cada idade ou etapa de desenvolvimento, a criança dispõe em cada microcultura, ou seja, em seu ambiente sociocultural imediato. Essa definição introduz uma primeira diferenciação na ideia de meio: o meio como ambiente, espaço de ação- ou "campo de aplicação de condutas" - e o meio como recurso ou instrumento de desenvolvimento. (CARVALHO, PEDROSA, FERREIRA, 2012. p.62)

\section{Observação 3}

Todos os dias as primeiras atividades são iniciadas na roda, pois nesse momento é construída a rotina junto com as crianças a partir do planejamento e das contribuições que elas trazem de casa. A roda é de conversa, sendo assim as 
crianças mostram suas novidades e contam suas novidades. Em seguida rotina vai sendo desenhada junto com elas. O tema do folclore foi desenvolvido a partir das brincadeiras de bola inserindo as cantigas. Uma das cantigas que as crianças se apropriaram foi a linda rosa juvenil. A professora, na roda, fez toda sua apresentação da rotina cotidiana e cantou a música. Em seguida estimulou as crianças a encenarem cada detalhe. Era escolhida uma criança para ser a rosa, a bruxa e o rei. As crianças de divertiam e elas mesmas se ofereciam para a encenação.

Através da brincadeira, dos gestos, movimentos e falas há uma composição de vozes e interações. Uma criança encena, a outra vai ao encontro para beijar, deita no chão e anuncia suas ações utilizando o corpo como forma de linguagem. Nesse ambiente a linguagem é a chave para compor as cenas, através dela há um diálogo com o corpo e sequência das cenas, a entrada na brincadeira e o diálogo entre as crianças inserindo-as no mundo social onde cada um tem um lugar estabelecido, mas por meio da brincadeira esse lugar pode mudar e ser adaptado. As crianças brincam, imitam, fantasiam e recriam a partir de um conhecimento que é construído por meio dessas experiências.

Nessa breve exposição podemos acenar para a importância do necessário diálogo entre a teoria e a prática e nesse processo, é indispensável pensar e executar um planejamento cuja ideia seja proporcionar ao sujeito a construção do conhecimento de maneira que o espaço, as relações e interações sejam instrumentos de aprendizagem, a brincadeira seja eixo norteador e a linguagem seja estimulada para a concretização do pensamento e as experiências contribuam para o arcabouço social, cultural na constituição do sujeito. 


\section{5. \\ Considerações finais}

A creche inicialmente é vista como um mal necessário e as mães trabalhadoras como sendo responsáveis pelo abandono do lar e filhos, pois às mulheres das classes abastadas destinava-se a maternidade enquanto que às pobres, o trabalho. As entidades de filantropia, nesse momento apoiam o Estado na busca por realizar os atendimentos sociais aos abandonados. E esse estigma percorreu por tempos, pois aqueles que não conseguiam conquistar a cidadania recebiam auxílio dos órgãos filantrópicos parceiros do Estado, mas se caracterizavam como indigentes, não cidadãos. Havia uma preocupação alimentar relacionada também com a higiene e segurança física. $O$ trabalho pensado na educação do sujeito e seu desenvolvimento intelectual e afetivo era pouco valorizado. A história da educação infantil foi tecida a partir do olhar assistencialista passando por toda transformação partindo para a evolução entendendo o cuidar e educar como algo indissociável. No entanto, é preciso ter clareza que a compreensão de criança, infância tem passado por inúmeras transformações modificando na forma de pensar e agir em relação à criança pequena.

No primeiro capítulo fundamentamos essa reflexão pontuando alguns aspectos da história da educação infantil. Em seguido ressaltamos a abordagem da proposta pedagógica. No próximo capítulo indicamos alguns artigos das Diretrizes Curriculares Nacionais para a educação infantil para dialogar posteriormente com a proposta pedagógica da escola apontada. Percebemos sintonia no que o documento mandatória direciona junto a proposta da escola observada.

No último capítulo identificamos a escola observada, apontamos os aspectos abordados na proposta pedagógica e finalizamos trazendo duas observações da prática cotidiana para fundamentar esse diálogo entre a teoria e a prática.

A concepção de infância referida pelo colégio é que a criança é compreendida como sujeito da história e que a constrói a partir das suas vivencias e experiências internas e externas. O cuidado é tratado como peça fundamental no processo educativo, transpassando pela instancia emocional e afetiva assim como o cuidado com o corpo conforme mencionado nas DCNEs. 
A proposta pedagógica aponta para a criança como centro do planejamento e a brincadeira como fundamental para estruturação das práticas cotidianas. Através das brincadeiras, as crianças constroem o conhecimento utilizando diferentes linguagens e interações diversas.

Os princípios éticos, políticos e estéticos são mencionados na proposta pedagógica do colégio e apresentados como pilares para a organização da proposta. Dessa forma, respeita-se a dignidade e os direitos das crianças, garantindo experiências relevantes de aprendizagens, criando oportunidades de por meio de inserção em diversificadas praticas sociais.

A proposta apresentada entende que ao planejar o currículo, deve-se considerar as especificidades de cada faixa etária vendo a criança como uma pessoa inteira.

Nos apontamentos mencionados sobre a proposta pedagógica do colégio, identificamos consonância e diálogo com as DCNEs. A linha teórica utilizada não fica evidente no documento, mas podemos que segue a linha sociointercionista Piaget, Vigotsky e Wallon. Visto que a maior preocupação do colégio é possibilitar trocas entre os sujeitos e o meio, entendendo as crianças como agente de aprendizagem.

O documento é avaliado e revisado a cada final do ano, pois há reformulação do plano de curso para o próximo ano. Em todo documento há uma preocupação na natureza da criança compreendendo, reconhecendo o jeito particular de estar no mundo e a sua formação integral.

Podemos concluir que, o documento apresenta com clareza qual criança ele quer formar e o papel do professor e da comunidade na organização curricular.

Com base na análise do documento e no aporte teórico usado no nosso trabalho também concluímos que há um trabalho planejado para crianças de 0 a 5 anos de idade, que garante a elas a possibilidade de aprender e desenvolver o aspecto afetivo, cognitivo e social tendo como ponto de partida o diálogo entre a proposta pedagógica, o plano curricular e o planejamento semanal. 


\section{6}

\section{Referências bibliográficas}

1 ANGELO, Adilson de. Espaço-tempo da fala na educação infantil: a roda de conversa como dispositivo pedagógico. In: Educação Infantil: Enfoques em diálogos. $3^{\text {a }}$ edição: Campinas, SP: Papirus, 2013

2 BRASIL. Lei n ${ }^{\circ}$ 9.394: Lei de Diretrizes e Bases da Educação Nacional (LDB). Diário Oficial da União, Brasília, Seção 1, p. 1-9, dez. 1996. Disponível em: http://www.planalto.gov.br/ccivil_03/Leis/L9394.htm. Acesso em: 20 set. 2016.

3 . Ministério da Educação. Secretaria de Educação Fundamental. Referencial curricular nacional para a Educação Infantil. Brasília: MEC/SEF, 1998. Ministério da Educação. Conselho Nacional de Educação. Resolução CEB n. 01, de 13 de abril de 1999: Institui as diretrizes curriculares nacionais para a educação infantil. Diário Oficial da República Federativa do Brasil, Brasília, p. 18, seção 1. 13 abr. 1999. - Ministério da Educação. Conselho Nacional de Educação.

Parâmetros Nacionais de Qualidade para a Educação Infantil. Brasília: MEC/SEB, 2006b.

6 Ministério da Educação. Conselho Nacional de Educação. Política

Nacional de Educação Infantil: pelo direito das crianças de zero a seis anos à Educação. Brasília: MEC/SEB, 2006d. - Ministério da Educação. Conselho Nacional de Educação.

Indicadores da Qualidade na Educação Infantil. Brasília: MEC/SEB, 2009b. de Educação. Resolução CEB n. 05, 17 dez. 2009. Institui as Diretrizes Curriculares Nacionais para a Educação Infantil. Diário Oficial República Federativa do Brasil, Brasília, DF, 18 dez. 2009a. Seção 1, p. 18. . Ministério da Educação. Conselho Nacional de Educação.

Parâmetros Básicos de Infraestrutura para Instituições de Educação Infantil. Brasília: MEC/SEB, 2009b. Presidência da República. Estatuto da Criança e do Adolescente. 
Lei nº8.069 de 13 Jul. 1990.

11

Presidência da República. Constituição 1988: Constituição da República Federativa do Brasil: promulgada em 5 de outubro de 1988. Brasília, DF.

12 . Presidência da República. Lei n⿳00024/61, 20 de Dezembro, 1961.

13 Ministério da Educação. Conselho Nacional de Educação. Plano Nacional de Educação, 2001.

14 . Ministério da Educação. Conselho Nacional de Educação. Resolução

Parecer 020/2009. Promulgada em 11 de novembro de 2011.

15 CARVAlHO, Ana M. A; PEDROSA, Maria Isabel; FERREIRA, Maria Clotilde Rossetti. O que é o meio? In: Aprendendo com a criança de zero a sesis anos. São Paulo: Cortez, 2012

16 CIVILETTI, Maria Vittoria Pardal. "O cuidado às crianças pequenas no Brasil escravista. In: Cadernos de Pesquisa, São Paulo: Fundação Carlos Chagas, n.76, p.31-40, fevereiro 1991.

17 DIAS, Fatima Regina Teixeira de Salles; FARIA, Vitoria Libia Barreto de. Currículo na Educação Infantil: Dialogando com os demais elementos da proposta pedagógica. São Paulo,: Scipione, 2011.

18 FARIA, Sonimar Carvalho. História e política de educação infantil. In: Educação Infantil em Curso. Fazolo, Eliane; CARVALHO, Maria Cristina M. P; LEITE, Maria Isabel F. P; Kramer, Sonia; Rio de Janeiro: Coleção da Escola de Professores.

19 FELIPE, Jane. O desenvolvimento infantil na perspectiva sociointeracionista: Piaget, Vygotsky, Wallon. In: Educação Infantil: Para que te quero? Porto Alegre: Artmed Editora, 2001.

20 GUIMARÃES, Daniela. Relações entre bebês e adultos na creche: o cuidado como ética. São Paulo: Cortez, 2011.

21 KISHIMOTO, TIZUKO Morchida. A pré-escola em São Paulo ( 1877-1940). São Paulo: Edições Loyola, Coleção Educar n.9, 1988.

22 KRAMER, Sonia. Propostas pedagógicas ou curriculares de educação infantil: para retomar o debate. Pro-Posições. vol. 13, N. 2 \{38\}- maio/ago. 2002.

23 Com a pré- escola nas mãos: uma alternativa curricular para e educação infantil. 14ed. São Paulo: Ática, 2005.

24 KUHLMANN, Moyses. "Instituições pré-escolares assistencialistas no Brasil 
(1899-1922 _ “In: Cadernos de Pesquisa, São Paulo: Fundação Carlos Chagas, n.78, p 17- 26, ago 1991.

25 LEITE FILHO, Aristeo. Educação infantil: uma história urgida. In: Educadora de Educadores: trajetórias e idéias de Heloisa Marinho. Rio de Janeiro: PUCRio 1997. Dissertação de Mestrado. P.20-30.

26 LÜDKE, Menga/ ANDRÉ, Marli E. D. A. Pesquisa em Educação: Abordagens qualitativas. São Paulo: EPU, 1986

27 NUNES. Maria Fernanda Rezende. Educação infantil: instituições, funções e propostas. In: Educação infantil: cotidiano e políticas/ Patrícia Corsino, (org.) - Campinas, SP: Autores Associados, 2009.

28 OLIVEIRA, Zilma de Morais Ramos. Novos tópicos na história da educação infantil no Brasil. In: Educação Infantil: fundamentos e métodos. $7^{a}$ edição. São Paulo: Cortez, 2011.

29 Os primeiros passos da história da educação infantil no Brasil. In: Educação infantil: fundamentos e métodos. $7^{\text {a }}$ edição. São Paulo: Cortez, 2011.

30

O currículo na educação infantil: $O$ que propõe as Novas Diretrizes Nacionais? Agosto. 2010.

31 VEIGA, Ilma Passos Alencastro. Perspectivas para reflexão em torno do projeto político pedagógico. In: Escola: espaço do projeto político pedagógico. 13ª Edição. Campinas, SP: Papirus, 1998. 